\title{
O desafio dos professores dos Anos Iniciais para o ensino da Matemática conforme a BNCC
}

\author{
Karine Pertile ${ }^{1}$ \\ Jutta Cornelia Reuwsaat Justo ${ }^{2}$
}

\section{RESUMO}

Este artigo tem como objetivo contribuir com a discussão sobre a Base Nacional Comum Curricular (BNCC). Além de discutir criticamente o documento, a partir de análises críticas já realizadas, apresenta-se a visão de supervisoras pedagógicas sobre o desafio a ser enfrentado pelos professores dos Anos Iniciais para ensinar Matemática na perspectiva da BNCC. O estudo, caracterizado como pesquisa ação, foi realizado por meio de um grupo de discussão com supervisores pedagógicos dos Anos Iniciais em um município do interior do Rio Grande do Sul. A análise dos dados deu-se por meio da Análise Textual Discursiva. As supervisoras compreendem que os professores dos Anos Iniciais precisam possuir conhecimento de conteúdo, conhecimento didático do conteúdo e conhecimento do currículo para ensinar Matemática, mas afirmam que eles não os têm, o pode repercutir no processo de aprendizagem.

PALAVRAS-CHAVE: Educação Matemática. Anos Iniciais do Ensino Fundamental. Formação Continuada de Professores. Base Nacional Comum Curricular.

The Challenge of Primary School Teachers for Teaching Mathematics According to the NCCB

\begin{abstract}
This article objective to contribute to the discussion on the National Common Curricular Base (NCCB). In addition to critically discussing the document, based on critical analyzes already carried out, it presents the
\end{abstract}

\footnotetext{
${ }^{1}$ Doutora em Ensino de Ciências e Matemática. Instituto Federal de Educação, Ciência e Tecnologia, Bento Gonçalves, Rio Grande do Sul, Brasil. https://orcid.org/0000-0002-7386-9861. karine.pertile@ gmail.com.

${ }^{2}$ Doutora em Ensino. Universidade Luterana do Brasil, Canoas, Rio Grande do Sul, Brasil. https://orcid.org/00000001-5110-1571.juttareuw@gmail.com.
} 
view of pedagogical supervisors about the challenge to be faced by teachers in the primary school to teach Mathematics according of NCCB. The study, characterized as action research, was realized by a discussion group with pedagogical supervisors from the primary school in a city in the interior of Rio Grande do Sul. The analysis of the data took place through the Discursive Textual Analysis. The supervisors understand that teachers in the primary school need to have knowledge of content, didactic knowledge of the content and knowledge of the curriculum to teach Mathematics, but claim that they do not have it, it can have repercussions on the learning process.

KEYWORDS: Mathematics Education. Continuing Education. Primary School. Common National Curriculum Base.

El Desafío de los Maestros de los Años Iniciales Para la Enseñanza de las Matemáticas según el BNCC

\section{RESUMEN}

Este artículo tiene como objetivo contribuir a la discusión sobre la Base Nacional Común Curricular (BNCC). Además de discutir críticamente el documento, basado en análisis críticos ya realizados, se presenta la opinión de los supervisores pedagógicos sobre el desafío que deben enfrentar los los profesores de los años iniciales de la Enseñanza Fundamental para enseñar matemáticas enseñar Matemáticas en perspectiva del BNCC. El estudio, caracterizado como investigación de acción, se llevó a cabo a través de un grupo de discusión con supervisores pedagógicos de los primeros años en una ciudad en el interior de Rio Grande do Sul. El análisis de los datos se realizó a través del análisis textual discursivo. Los supervisores entienden que los profesores de los años iniciales necesitan tener conocimiento del contenido, conocimiento didáctico del contenido y conocimiento del plan de estudios para enseñar Matemáticas, pero afirman que no lo tienen, puede tener repercusiones en el proceso de aprendizaje.

PALABRAS CLAVE: Educación Matemática. Formación continua de profesores. Años Iniciales de la Enseñanza Fundamental. Base Nacional Común Curricular. 


\section{Introdução}

Este artigo apresenta um excerto dos resultados da pesquisa ${ }^{3}$ de doutorado da primeira autora, orientada pela segunda, cujo objetivo foi investigar as contribuições didático-matemáticas de um grupo de discussão com supervisores pedagógicos sobre a Matemática dos Anos Iniciais do Ensino Fundamental (EF) na Base Nacional Comum Curricular (BNCC) (BRASIL, 2017).

Com a homologação da BNCC (BRASIL, 2017) para a Educação Infantil e para o Ensino Fundamental em dezembro de 2017, a rede municipal de ensino de Bento Gonçalves/RS buscava meios de formação para seus professores para adequar o ensino ao que a BNCC (BRASIL, 2017) estabelece. Ao procurarmos a Secretaria Municipal de Educação (SMED) da cidade, para realização da pesquisa de doutorado, identificamos a necessidade da formação de supervisores pedagógicos dos Anos Iniciais, para que estes pudessem guiar os professores e orientar o cumprimento do currículo, em relação à Matemática dos Anos Iniciais. Desta forma, organizamos uma formação, na modalidade de grupo de discussão, com supervisores pedagógicos, com a finalidade de discutir, estudar, refletir sobre e analisar a Matemática nos Anos Iniciais do EF, a partir dos objetos de conhecimento, das habilidades, das competências específicas e do processo de ensino da Matemática para os Anos Iniciais, conforme a BNCC (BRASIL, 2017), de modo a contribuir com os conhecimentos didático-matemáticos dos participantes.

Entre as atribuições do supervisor pedagógico, segundo o Edital 04/2018 do último concurso municipal de Bento Gonçalves/RS, destacamos "acompanhar e assessorar as atividades do corpo docente em questão de currículo, métodos, técnicas e integração entre os conteúdos específicos" (BENTO GONÇALVES, 2018, p. 24). Ou seja, para além de um papel de

\footnotetext{
${ }^{3}$ O projeto de pesquisa foi submetido ao Comitê de Ética da Universidade Luterana do Brasil, através da Plataforma Brasil, e aprovado sob o parecer de número 2.928.749.
} 
fiscalização, o supervisor pedagógico atua junto ao professor para acompanhálo e assessorá-lo no processo de ensino.

Esse papel da supervisão vai ao encontro do entendimento de Alarcão (2001) de que o objeto da supervisão pedagógica está na qualidade do ensino, "porém os critérios e a apreciação da qualidades não são impostos de cima para baixo numa perspectiva de receituário acriticamente aceito pelos professores, mas na interação entre o supervisor e os professores" (ALARCÃO, 2001, p. 10).

Assim, entendemos que, ao realizarmos o grupo de discussão com os supervisores pedagógicos dos Anos Iniciais do EF, os estudos concretizados poderiam repercutir no trabalho pedagógico a ser desenvolvido pelos professores dos Anos Iniciais.

$\mathrm{O}$ presente artigo tem o propósito de discutir criticamente a BNCC (BRASIL, 2017), a partir das análises críticas realizadas por Aguiar (2018), Lopes (2018), Oliveira (2018), Passos e Nacarato (2018), Rolkouski (2018) e Ornelas e Silva (2019). E, por fim, contribuir com a discussão sobre a BNCC, trazendo a visão de supervisoras pedagógicas sobre o desafio a ser enfrentado pelos professores dos Anos Iniciais para ensinar Matemática na perspectiva da BNCC.

\section{A Base Nacional Comum Curricular - BNCC}

A BNCC (BRASIL, 2017) é apresentada como sendo a referência nacional para a formulação dos currículos dos sistemas e das redes escolares dos Estados, do Distrito Federal e dos Municípios e das propostas pedagógicas das instituições escolares. Segundo o próprio documento (BRASIL, 2017), a BNCC vai contribuir para o alinhamento de outras políticas e ações, em âmbito federal, estadual e municipal, referentes à formação de professores, à avaliação, à elaboração de conteúdos educacionais e aos critérios para a oferta de infraestrutura adequada para o pleno desenvolvimento da educação.

Segundo a BNCC (BRASIL, 2017), os documentos norteadores que 
serviram de base para a sua elaboração foram os PCNs (BRASIL, 1998) e as DCNs (BRASIL, 2013). Lopes (2018), no entanto, afirma que não são esses documentos que devem orientar a elaboração de um currículo, pois este deveria ser elaborado a partir de

[...] livros didáticos e literatura educacional, formação inicial e continuada de professores, avaliações centralizadas, projetos em parcerias Universidade-Escola e por meio de tantas outras ações que constituem o que, de forma geral, podemos denominar tradições curriculares. As disciplinas escolares e suas comunidades, por exemplo, são dispositivos sociais que se destacam na orientação curricular e compõem tais tradições (LOPES, 2018, p. 24).

Também em direção a uma construção plural de currículo, Aguiar (2018) aponta que

É preciso pensar a educação em sua totalidade. Temos a convicção de que currículo, a partir de diretrizes nacionais, é definido nas instituições educativas e escolas, construído a muitas mãos, a partir das várias histórias de vida que fazem parte desse cotidiano. As concepções, saberes, conteúdos e as metodologias não fazem sentido se desconectadas daquele contexto. Os estudantes e os profissionais da educação devem ter assegurado seu protagonismo (AGUIAR, 2018, p. 18).

Em outras palavras, Lopes (2018) e Aguiar (2018) defendem a ideia de que um currículo deve ser elaborado de forma coletiva, envolvendo os atores do processo educacional. Defendemos a ideia de que um currículo precisa ser construído no âmbito acadêmico e profissional, no diálogo entre os atores da educação e a literatura educacional.

Embora o Movimento Pela Base (MPB) ${ }^{4}$ afirme que diversas entidades,

\footnotetext{
${ }^{4}$ Movimento pela Base. Disponível em: < http://movimentopelabase.org.br/>. Acesso em 02 out. 2019.
} 
entre elas universidades, escolas, secretarias, entidades da sociedade civil, professores e especialistas em educação, foram consultadas para a construção da BNCC (BRASIL, 2017), muitos são os autores que criticam a falta de discussão na elaboração desta, em especial academicamente (OLIVEIRA, 2018; LOPES, 2018; ROLKOUSKI, 2018). Nessa direção, Imbernón (2010) já criticava os processos elaborados apenas por uma equipe hierárquica, defendendo que,

[...] sem a participação dos professores, qualquer processo de inovação pode se converter em uma ficção ou em jogo de espelhos que pode, inclusive, chegar a refletir processos imaginários, quando não simplesmente uma mera alteração técnica ou terminológica promovida a partir do topo (IMBERNÓN, 2010, p. 26).

Afinal, são os professores e gestores da educação que realmente compreendem a instituição escolar e a forma como o ensino e a aprendizagem ocorrem. Mas por que se afirma que não houve participação da comunidade educacional? Resumimos aqui o que é apontado por Passos e Nacarato (2018): A primeira versão da BNCC, elaborada em 2015, contou com a participação de pesquisadores da área da Educação Matemática, além de ter sido analisada criticamente por pesquisadores e especialistas, tendo sido disponibilizada para consulta pública de professores do país. "Pode-se dizer que, embora de forma reduzida, houve a participação da comunidade." (PASSOS; NACARATO, 2018, p. 124). As autoras, inclusive, participaram da avaliação do documento. A consulta pública foi levada em consideração para a segunda versão, além de recomendações e sugestões de pareceristas e representantes de sociedades científicas. Após o impeachment da presidenta Dilma, a equipe que trabalhava na elaboração da BNCC foi destituída e outra equipe foi constituída, com especialistas convidados e com representantes de grupos empresariais, como a Fundação Lemann. Foi essa equipe, então, que elaborou a terceira versão, enviada ao Conselho Nacional de Educação e, com 
algumas modificações, foi homologada em dezembro de 2017. Embora as autoras não citem, a terceira versão foi construída com alterações e omissões em relação à segunda versão.

O MPB, embora afirme que "A BNCC não é a única solução para a Educação brasileira”, assegura que a BNCC (BRASIL, 2017) é uma oportunidade para que soluções, no âmbito da Educação Básica, sejam pensadas e realizadas. Ao deixar claro o que os alunos brasileiros devem aprender, o MPB afirma que o documento pode ajudar a diminuir as desigualdades educacionais e a melhorar a qualidade da Educação.

Embora a BNCC (BRASIL, 2017) seja apresentada para desenvolver o pleno desenvolvimento da educação, muitos são os autores que desacreditam que a BNCC possa contribuir para a melhoria da educação. Para Lopes (2018), a ideia de que as metas de aprendizagem serão garantidas através de uma mesma proposta curricular, oculta a problemática da desigualdade social associada à educação.

Se há desigualdades no sistema educativo - e essas desigualdades existem - isso se deve ao investimento diferenciado na carreira do professor e nas condições de trabalho nas escolas, nas condições de vida das famílias e nas condições de estudo dos alunos e alunas (LOPES, 2018, p. 25).

Oliveira (2018) também aponta para o equívoco de acreditar que haverá melhoria na aprendizagem por meio da BNCC (BRASIL, 2017).

[...] a BNCC pressupõe, equivocadamente, que a melhoria da qualidade das aprendizagens seria produzida por meio de um currículo único para estudantes de todo o país, controlado de fora da escola por avaliações de larga escala e material didático padronizado, além de um sistema de prêmios e castigos destinado ao controle de docentes, gestores e estudantes (OLIVEIRA, 2018, p. $56)$. 
Além disso, o currículo único tem sido fortemente criticado. Ignorar as especificidades de cada escola, de cada região, de cada realidade em um país tão plural quanto o Brasil, é apontado por alguns autores como um equívoco para a educação, tal como afirma Oliveira (2018, p. 58): "Para origens diferentes, necessidades diferentes, características sociais, culturais e econômicas diferentes, é preciso oferecer trajetórias diferentes! Tratar igualmente os desiguais é aprofundar a desigualdade!".

Nos questionamos, no entanto, se os autores apresentados levaram em consideração que a BNCC (BRASIL, 2017) determina apenas $60 \%$ dos conteúdos dos currículos. O que concebemos é que, sem orientações claras e específicas, os professores podem basear suas aulas apenas no que a BNCC (BRASIL, 2017) preconiza, ignorando, portanto, a importância das especificidades regionais que podem corresponder a $40 \%$ do currículo.

Rolkouski (2018), em um estudo comparativo entre a BNCC (BRASIL, 2017) e o Pacto Nacional para Alfabetização na Idade Certa (PNAIC), além de questionar o processo de alfabetização - e o que o MEC propõe como alfabetização - até o $2^{\circ}$ ano do $\mathrm{EF}$, critica, em relação à alfabetização matemática na BNCC, a ausência de discussões sobre a importância do lúdico no processo de aprendizagem dos três primeiros anos, sobretudo para a alfabetização. Além disso, "a especificidade do trabalho pedagógico [no ensino de Matemática] com os três primeiros anos ficou suprimida nas considerações gerais" (ROLKOUSKI, 2018, p. 127). O autor critica o detrimento do PNAIC e projetos relacionados a ele, em função da BNCC.

Passos e Nacarato (2018) corroboram com as ideias de Rolkouski (2018), ao afirmarem que o PNAIC foi um programa de grande valia para os Anos Iniciais do EF, em especial à formação continuada de professores. Em relação à BNCC (BRASIL, 2017) e à Matemática nos Anos Iniciais, para as autoras, 
como o fez, não dá subsídios ao professor que não tem uma formação específica para ensinar Matemática e que, o modo como as habilidades foram redigidas dificilmente serão por ele compreendidas. Portanto, muitos são os desafios para a implementação desse documento e são poucas animadoras as ações até aqui apresentadas para garantir o mínimo de conhecimento para o professor trabalhar com segurança (PASSOS; NACARATO, 2018, p. 131).

Em relação ao ensino e à aprendizagem de Matemática, Passos e Nacarato (2018) afirmam que estudos sobre a Educação Matemática não foram levados em consideração pelos responsáveis pelas reformas curriculares, "até porque a maioria dos educadores matemáticos rejeita a ideia de um currículo por competências e habilidades, tal como propõe a BNCC, numa visível articulação com o mundo empresarial.” (p. 120).

Na mesma perspectiva, Ornelas e Silva (2019) afirmam que BNCC (BRASIL, 2017) "é composta por delimitações indicadas pelas unidades temáticas das áreas de conhecimento” (p. 322). As autoras, baseando-se no pensamento de Young, que defende um currículo fundamentado no conhecimento, alegam que a BNCC está na contramão disso, por defender um currículo organizado em habilidades e competências. Para as autoras, "a BNCC, ao chamar atenção para competências e habilidades de forma técnica (como é apresentada pelo código alfanumérico), evidencia os conteúdos como um “instrumento de gestão do ensino"' (ORNELAS; SILVA, 2019, p. 321).

Outro ponto comum aos textos de Oliveira (2018), Lopes (2018) e Passos e Nacarato (2018) é a proximidade das habilidades presentes na BNCC (BRASIL, 2017) com as matrizes de referência das avaliações externas, o que nos deixa importantes questionamentos: A melhoria na educação será medida pelos resultados brasileiros em avaliações externas? A BNCC não se apresenta como um documento que visa a formação integral do aluno?

Nenhum dos autores estudados até este ponto cita ou identifica a 
existência das Orientações on-line ${ }^{5}$ (BRASIL, [2018])6, o que pode ser vinculado ao fato deste material não estar anexado à BNCC (BRASIL, 2017). Acreditamos que esta seja uma falha significativa, visto que o material possui comentários explicativos sobre as habilidades e sugestões para a elaboração dos currículos estaduais e municipais. A falta de conhecimento do mesmo pode levar a uma leitura superficial e/ou equivocada da BNCC (BRASIL, 2017). Um exemplo disso é encontrado em Passos e Nacarato, ao afirmarem que

[...] no campo de probabilidade, pouco explorado pelos professores, identificamos que a forma como as habilidades foram elencadas pouco contribuirá para as práticas docentes, visto que a chamada "progressão ano a ano", que consta nas orientações iniciais, sugerindo a ideia de um currículo em espiral, de fato não acontece; há apenas mudanças na linguagem até o $4^{\circ}$ ano, com uma introdução brusca no $5^{\circ}$ ano do cálculo de probabilidade (PASSOS; NACARATO, 2018, p. 129).

As autoras estão corretas em sua afirmação, visto que, com apenas o texto apresentado na BNCC, o leitor tem a impressão de que não é introduzido o cálculo de probabilidade no $4^{\circ}$ ano. As orientações on-line (BRASIL, [2018]), porém, indicam o cálculo da probabilidade ainda no $4^{\circ}$ ano, mas sem a utilização de frações, o que será inserido no $5^{\circ}$ ano.

As orientações on-line (BRASIL, [2018]) também atentam para a importância de materiais lúdicos e concretos para a aprendizagem da Matemática nos Anos Iniciais, o que também contraria o citado por Rolkouski (2018) sobre a falta de importância dada ao lúdico nos primeiros anos do EF. Novamente criticamos a falta de divulgação das orientações on-line (BRASIL, [2018]), visto que o documento contém informações importantes e relevantes

\footnotetext{
${ }^{5}$ As orientações a que nos referimos estão disponíveis no sítio da BNCC, sob a denominação de "BNCC em Planilha". Nelas, os professores têm acesso a informações complementares, tais como explicações sobre as habilidades e indicações de atividades.

${ }^{6}$ BNCC em Planilha. Disponível em: <http://download.basenacionalcomum.mec.gov.br/>. Acesso em 02 fev. 2019.
} 
aos processos de ensino e aprendizagem.

Para encerrar - esta seção, pois acreditamos que a discussão sobre a BNCC (BRASIL, 2017) deve ser contínua -, apresentamos o argumento de Lopes (2018), com a qual concordamos. A autora defende que, mesmo com um currículo igual, este sempre será interpretado de maneiras diferentes nas escolas.

Uma base curricular, por mais detalhada e explícita que seja, será lida contextualmente de formas diferentes. Professores e professoras com formações diferentes, escolas com diferentes condições de trabalho, histórias de vida diferentes dos alunos e alunas, docentes com salários e comprometimentos distintos com a prática educacional, interesses diferentes e, sobretudo, relações dinâmicas entre sujeitos e contextos farão com que o currículo seja interpretado de forma diferente (LOPES, 2018, p. 26).

Apesar de todas as críticas apresentadas, a BNCC (BRASIL, 2017) é um documento normativo que está em vigor. Embora apoiemos os autores supracitados sobre as limitações e implicações da BNCC, a nós, pesquisadores e educadores, cabe tentar auxiliar ao máximo o processo de ensino, em especial na Educação Básica. Pois, como apontaram Passos e Nacarato (2018), a BNCC não dá subsídios para o professor que não tem formação em Matemática. Desta forma, através da formação continuada com supervisores pedagógicos dos Anos Iniciais, nosso objetivo na formação foi fornecer subsídios a estes, de tal forma que possam apoiar os professores de suas escolas no processo de ensino e, assim, contribuir com a aprendizagem da Matemática neste nível de escolaridade.

\section{Metodologia}

A pesquisa foi realizada por meio de formação continuada, com um grupo de discussão sobre a Matemática dos Anos Iniciais presente na BNCC 
(BRASIL, 2017).

Participaram do grupo de discussão dez supervisoras pedagógicas dos Anos Iniciais do EF e uma representante da SMED, responsável pelo desenvolvimento de projetos realizados no âmbito dos Anos Iniciais nas escolas do município. As supervisoras foram convidadas pela SMED e sua participação deu-se de forma voluntária. A formação teve 30 horas de duração, ocorrendo entre os meses de setembro e novembro de 2018.

Dentre as dez supervisoras, oito eram licenciadas em Pedagogia, o que nos permitiu inferir dados sobre os professores dos Anos Iniciais, com base nas narrativas dessas ao longo da formação. As demais eram formadas em: licenciatura em Ciências e licenciatura em Letras. A representante da SMED era licenciada em Matemática.

A composição do grupo de discussão foi iniciativa nossa, para fins de pesquisa de doutorado, mas atendeu aos esforços que a SMED já vinha realizando no sentido de buscar uma formação, em relação à BNCC (BRASIL, 2017), para os supervisores dos Anos Iniciais, de modo que estes pudessem auxiliar os professores no processo de ensino da Matemática nos Anos Iniciais das escolas municipais.

Em consonância com esta necessidade, entende-se a pesquisa como pesquisa-ação, na perspectiva de Vergara (2000). Características de uma pesquisa-ação, segundo Zeichner (1997, 2003) e Pimenta (2005), também são vislumbradas na investigação, como: (i) fornece um meio de os supervisores engajarem-se na análise da prática de ensino em Matemática e, assim, aprofundarem suas bases de conhecimento didático-matemáticas nos anos iniciais do EF; (ii) tem como objetivo comum discutir e refletir sobre a Matemática dos Anos Iniciais na BNCC (BRASIL, 2017); (iii) provê, aos participantes da pesquisa, momentos de reflexão sobre as dimensões sociais e políticas de seu trabalho pedagógico; (iv) torna consciente saberes implícitos dos participantes, de tal forma a serem examinados, reavaliados e melhorados no processo de ensino; e (v) envolve esforços no sentido de encorajar e apoiar a colaboração dos participantes a partir de suas próprias práticas, seja como 
docentes ou como supervisores pedagógicos.

Os encontros do grupo de discussão foram gravados em áudio, com autorização prévia das participantes, que assinara o Termo de Consentimento Livre e Esclarecido. Foram observados, analisados e registrados em diário de campo da pesquisadora, comportamentos, questionamentos, ações e reflexões das participantes ao longo dos encontros do grupo. Os nomes das supervisoras, participantes do grupo, foram alterados a fim de preservar sua identidade. Foi escolhido o seguinte código para nominá-las: "Sup", seguido de uma das letras do alfabeto, de A a J. A ordem de escolha destas deu-se conforme suas manifestações durante os encontros do grupo. Ou seja, a primeira a manifestar-se foi chamada de SupA, a segunda de SupB e, assim, sucessivamente.

As narrativas das supervisoras, participantes do grupo de discussão, registradas do diário de campo da pesquisadora e as transcrições das gravações em áudio dos encontros do grupo foram inicialmente analisadas sob uma perspectiva descritiva interpretativa, sustentadas em teóricos da Educação e da Educação Matemática.

Os textos oriundos da análise descritiva interpretativa constituíram o corpus da investigação, que foi analisado por meio da Análise Textual Discursiva (MORAES; GALIAZZI, 2007), que corresponde a uma metodologia de análise de dados e informações de natureza qualitativa com a finalidade de produzir novas compreensões sobre fenômenos e discursos.

Para este artigo, apresentamos uma das categorias emergentes da análise, relativa aos desafios dos professores dos Anos Iniciais em ensinar a Matemática prevista na BNCC, na perspectiva das supervisoras pedagógicas. 


\section{Os Professores dos Anos Iniciais e o Ensino da Matemática da BNCC na Visão das Supervisoras Pedagógicas}

Embora tenhamos optado por um texto único, apresentamos aqui algumas subcategorias: Conhecimento de conteúdo, conhecimento didático do conteúdo e conhecimento de currículo do professor dos Anos Iniciais; Professor e aprendizagem de Matemática nos Anos Iniciais; Professor como agente social; Professor e linguagem matemática nos Anos Iniciais; Professor e o uso de materiais nas aulas de Matemática nos Anos Iniciais; e Prática Reflexiva.

Durante os encontros do grupo de discussão, as supervisoras demonstraram não acreditar que os professores dos Anos Iniciais estivessem suficientemente preparados para ensinar matemática conforme o currículo organizado com base na BNCC (BRASIL, 2017), em função de sua formação inicial. A SupC, inclusive, citou que a formação dos professores dos Anos Iniciais, antes mesmo da implantação da BNCC, já estava abaixo do nível esperado para atender às demandas de sala de aula.

A fala da supervisora vai ao encontro dos estudos realizados sobre cursos de licenciatura em Pedagogia ofertados em diferentes universidades brasileiras nas últimas duas décadas (CURI, 2004; ALMEIDA; LIMA, 2012; OLIVEIRA, 2012; ABRAHÃO; SILVA, 2017), em relação à Matemática. As pesquisas concluem que a formação matemática ofertada pela licenciatura em Pedagogia é insuficiente para o aprendizado do professor que ensina Matemática nos Anos Iniciais do EF.

Para Shulman (2014), se o conhecimento do professor fosse organizado em um manual, deveria incluir as seguintes categorias de base: conhecimento do conteúdo; conhecimento pedagógico do conteúdo; conhecimento do currículo; conhecimento pedagógico geral; conhecimento dos alunos e suas 
características; conhecimento de contextos educacionais; conhecimento dos fins, propósitos e valores da educação; com ênfase nas três primeiras categorias.

$\mathrm{O}$ conhecimento do conteúdo refere-se às compreensões do professor sobre a estrutura da disciplina, à forma como ele entende o conhecimento que será objeto de ensino. (SHULMAN, 2014).

O conhecimento pedagógico do conteúdo se refere aos modos de formular e apresentar o conteúdo, para torná-lo compreensível aos alunos. Este é também o conhecimento que se refere à compreensão docente do que facilita ou dificulta o aprendizado discente de um conteúdo em específico. Para Shulman (2014), o conhecimento pedagógico de conteúdo é o que distingue a compreensão de um especialista em um assunto da de um professor.

A terceira categoria apontada por Shulman (2014), o conhecimento do currículo, refere-se ao conhecimento do professor acerca dos programas de ensino, dos recursos didáticos que podem ser utilizados, o conhecimento das relações entre conteúdos e contextos, e a familiaridade com os outros tópicos desse conteúdo que já foram ou serão estudados na mesma disciplina nos anos anteriores e posteriores.

As supervisoras, durante momentos da discussão, identificaram que os professores dos Anos Iniciais, embora tenham por vezes o conhecimento de conteúdo, nem sempre têm o conhecimento pedagógico do conteúdo. Um exemplo disso foi a fala da SupI, durante a discussão sobre o desenvolvimento da habilidade de realizar cálculos mentais. A supervisora afirmou acreditar que os professores sabem como realizar cálculos mentais, mas não seriam capazes de ensinar isso aos alunos. Em outro momento, a mesma supervisora apontou a necessidade de o professor ter, na sua formação básica, não só contato com o conteúdo a ser ensinado, mas com a didática, para que saiba ensinar da melhor forma o conteúdo.

Ball e colaboradores (2003, 2005, 2008) dão suporte à fala da supervisora, ao enfatizarem que é necessário que o professor saiba bem os 
conteúdos matemáticos que ensina para ajudar os alunos na aprendizagem, embora não seja suficiente para o ensino apenas ter domínio sobre o conteúdo. Para Serrazina (2012), a formação matemática dos professores dos Anos Iniciais precisa ser didática e matemática, na perspectiva do que Godino (2009) denomina "conhecimento didático-matemático". Ou seja, além de dominar o objeto de ensino, é preciso conhecer recursos metodológicos que favoreçam o processo de ensino. Para ilustrar essa questão, ao discutirmos sobre aprendizagem dos algoritmos de multiplicação e de divisão, as participantes afirmaram que muitas vezes nem o professor tem a compreensão dos processos, o que causa insegurança e fragilidade no processo de ensino.

Além do conhecimento sobre o conteúdo e o sobre os recursos metodológicos para o ensino, a SupH afirmou a importância de os professores entenderem o porquê do ensino de certos conteúdos em determinado ano. Baseando-nos no que Shulman (2014) e Tardif (2014) assinalam quanto ao conhecimento do currículo como essencial à prática docente, defendemos que os professores dos Anos Iniciais não necessitam apenas saber sobre os objetos e habilidades do ano escolar para o qual lecionam. É preciso que conheçam, também, o que o aluno desenvolveu na série anterior e como deve prepará-lo para a série seguinte. Ainda, Cunha (2010) afirma que as maneiras como conteúdos e atividades são propostos influenciarão a forma como os alunos, posteriormente, irão encarar e relacionar os conhecimentos matemáticos.

Além disso, a SupI declarou que o professor não é um sujeito neutro no processo de ensino e aprendizagem, no sentido da formação social do aluno. Nessa perspectiva, Freire (1996) apontou o professor como agente social, afirmando que ser professor é compreender que a educação é uma forma de intervenção no mundo. Na mesma linha, Alarcão (1996) defende que o papel do professor não é meramente técnico, que ele tem papel ativo na educação.

Ao compreender o papel do professor como agente social, a supervisora refletiu ético/politicamente, o que é citado por Zeichner (2003) como análise das ações docentes e suas repercussões no contexto escolar, nas estruturas 
sociais e nas instituições.

Relacionando o professor ao processo de aprendizagem da Matemática, a SupI indicou que muitas vezes o problema de aprendizagem não está no aluno, mas na falta de preparação do professor em relação ao ensino. A SupG, argumentando que o professor se preocupa com o cumprimento do currículo, apontou que o professor não respeita o tempo para os alunos pensarem.

Para Ponte e Oliveira (2002), o conhecimento dos processos de aprendizagem, que dizem respeito ao saber do professor sobre o seu aluno e sobre a forma pela qual ele aprende, compõe o conhecimento didático necessário à prática docente. Esse conhecimento é fundamental para o sucesso na atividade de ensinar e, consequentemente, para o processo de aprendizagem. Não basta cumprir integralmente o currículo se os alunos não conseguiram aprender os conteúdos ensinados. Os autores (PONTE; OLIVEIRA, 2002) ainda indicam que o professor deve ter conhecimento instrucional, que contempla tudo o que diz respeito à condução efetiva das situações de aprendizagem. Aqui, são incluídos os planejamentos, tanto de curto quanto de médio e longo prazos, bem como tudo o que envolve a estruturação das aulas de Matemática. Tal conhecimento é fundamental para a organização dos trabalhos dos alunos, a criação e variação de recursos metodológicos em sala de aula, bem como a avaliação da aprendizagem dos alunos e do ensino. Serrazina (2012) afirma como imprescindível ao professor que ensina Matemática avaliar as aprendizagens dos alunos, tomando decisões sobre como continuar o seu ensino.

Uma das supervisoras, além de defender que os professores compreendam o que vão ensinar, afirmou que eles precisam ser incentivadores do desenvolvimento da autonomia e do protagonismo discente na busca das soluções de problemas, valorizando as diferentes formas de registro e solução. $\mathrm{Na}$ mesma perspectiva, outra supervisora asseverou que o professor também precisa saber como corrigir os alunos, quando necessário. Esta discussão direcionou para outro saber necessário ao professor que ensina Matemática, defendido por Serrazina (2012): o professor deve saber como 
interpretar e julgar, do ponto de vista matemático e didático, questões, resoluções, problemas e observações de seus alunos.

Em relação à linguagem matemática, a BNCC (BRASIL, 2017) cita a necessidade de o professor utilizar a linguagem correta no processo de ensino. Curi (2004), ao considerar que os professores concluem a licenciatura em Pedagogia sem conhecimento matemático necessário para o ensino, afirma que há falhas na formação no que concerne a procedimentos relativos à prática docente. A autora declara que uma das defasagens da formação desses professores está relacionada com a linguagem matemática do professor que vai ensinar Matemática.

Nesta perspectiva, em alguns momentos do grupo de discussão, pudemos observar que as supervisoras também não dominavam a linguagem matemática. Além dos termos que essas não conheciam, tais como: algoritmos, fatos básicos, campos numéricos, disposição retangular, tabelas de duplas entrada, retas transversais, entre outros, as supervisoras ainda apresentaram linguagem muito semelhante à infantil, referindo-se a características ou propriedades de objetos geométricos. Por exemplo, ao serem questionadas sobre o que é um ângulo, uma das supervisoras apontou ser "aquele cantinho".

Um tópico relevante, citado muitas vezes pelas Orientações on-line (BRASIL, [2018]) da BNCC, é que no $1^{\circ}$ ano do EF, os alunos não precisam utilizar-se da notação matemática formal para registro. "Fazer registros diversos também deve ser incentivado como parte do processo de construção da linguagem matemática, da ampliação do raciocínio e da capacidade de argumentação dos alunos" (BRASIL, [2018], s.p.). Defendemos, assim, que o professor precisa estar preparado para auxiliar o aluno nesses registros, que podem ser, por exemplo, em forma de desenhos ou utilizando a linguagem materna. Essa questão foi referendada pelas supervisoras, durante as discussões, quanto a necessidade de o professor saber orientar o aluno nesses registros. Serrazina (2012) contempla os saberes do professor que ensina matemática, entre eles, representar ideias matemáticas de diferentes formas, 
sendo capaz de fazer correspondências entre representações concretas, icônicas e simbólicas.

Para o $1^{\circ}$ ano do EF, as orientações on-line da BNCC (BRASIL, [2018]) propõe o ensino de forma mais lúdica. Uma das supervisoras afirmou que é preciso que os professores quebrem seus próprios paradigmas e reaprendam a ensinar no $1^{\circ}$ ano. Para Zeichner (2003), uma nova prática implica sempre uma reflexão sobre a sua experiência, as suas crenças, imagens e valores. É um momento de refletir e reavaliar o processo de ensino, e suas teorias tácitas sobre este.

A SupI apontou a importância de o professor saber por quê está utilizando determinado material. Para a supervisora, não é suficiente que o professor se utilize de materiais concretos em aula, se estes não gerarem questionamentos, reflexões e conhecimento aos alunos. Ou seja, o material concreto deve ter finalidade pedagógica. A questão levantada pela supervisora aponta alguns dos aspectos esperados para o professor que ensina Matemática, conforme Serrazina (2012). A autora afirma que o docente necessita saber avaliar a qualidade matemática dos materiais de ensino disponíveis e, além disso, fazer bons questionamentos, de modo que os alunos progridam na aprendizagem matemática. Shulman (2014) ainda afirma que os professores precisam estar familiarizados com os materiais de ensino.

Embora a maior parte das supervisoras tenham apontado que os professores não estão aptos para o ensino da Matemática nos Anos Iniciais conforme é apresentada na BNCC (BRASIL, 2017), Shulman (2014) indica que um dos conhecimentos necessários à profissão docente está relacionado à sabedoria que o professor adquire com a prática, sendo que esta provém da racionalização reflexiva sobre sua prática.

A prática reflexiva implica compreender que a formação consiste num processo contínuo. O professor está em contínua formação e pode fazer desse processo também fonte de reflexão e aprendizado na medida em que problematiza os processos de ensino e de aprendizagem. Especialmente em uma situação de mudança de políticas públicas educacionais, como a que 
ocorre atualmente no País.

$\mathrm{Na}$ perspectiva de uma prática docente reflexiva, Zeichner (2003) considera que há aspectos constituintes, como estar atento aos contextos culturais e institucionais, envolver-se na mudança e tornar-se agente do seu próprio desenvolvimento profissional. Segundo Schön (2007), as exigências para a formação dos profissionais reflexivos não se detêm apenas em uma instância. Ele aponta para a necessidade de os professores adquirirem um olhar de criticidade que ultrapassa o mero pensar sobre a prática, caracterizando um exercício paciente que se desenvolve no decorrer do processo de maneira que as ações sejam problematizadas, revistas, repensadas e reconstruídas constantemente. Ao refletir e analisar as problemáticas da sala de aula, o professor desenvolve o conhecimento profissional, citado por Ponte e Oliveira (2002). Pimenta (1995) também afirma que a formação docente não se esgota nos cursos de formação, sendo a prática essencial para a formação dos professores.

\section{Conclusão}

O grupo de discussão oportunizou às participantes abertura às discussões, fazendo com que se sentissem à vontade para expor suas dúvidas, crenças e fragilidades em relação à Matemática e ao ensino de Matemática, o que nos permitiu ter uma noção mais aprofundada sobre a linguagem e conceitos matemáticos compreendidos pelas supervisoras. Verificamos que, à medida que as discussões foram tornando-se mais cooperativas, as participantes sentiram-se parte do grupo, identificando-se umas como as outras, em relação a suas fragilidades, anseios e expectativas. A dinâmica do grupo de discussão permitiu às supervisoras momentos de troca, reflexão sobre si e sobre sua prática pedagógica e tomadas de consciência sobre a importância das discussões.

Ao se perceberem como um grupo de discussão que colabora para a aprendizagem, as supervisoras passaram a compreender melhor a 
Matemática, de tal forma a perceber a BNCC (BRASIL, 2017) interligada com recursos metodológicos, no que tange ao trabalho dos professores nos Anos Iniciais. E, como supervisoras, poderão acompanhar e assessorar com mais segurança e compreensão as atividades do corpo docente, no que diz respeito ao ensino de Matemática.

Por meio do aporte teórico, estudamos que entre os saberes necessários ao professor que ensina Matemática está o conhecimento matemático para o ensino, que se refere ao conhecimento que o professor necessita para saber ensinar Matemática. Durante as discussões do grupo, verificamos que as supervisoras pedagógicas compreendem que os professores dos Anos Iniciais precisam possuir conhecimento de conteúdo, conhecimento didático do conteúdo e conhecimento do currículo para ensinar Matemática, mas afirmam que eles não os têm. As participantes do grupo de discussão afirmaram, inclusive, que os professores que ensinam Matemática para os Anos Iniciais não possuem conhecimento de conteúdo matemático e, portanto, não há possibilidade de possuírem o conhecimento matemático para o ensino. Ou seja, não há como saber como ensinar, se não se sabe o quê ensinar. Em nosso entendimento os aspectos referentes a conteúdos e metodologias de ensino são essenciais na formação do professor, já que o professor dos Anos Iniciais será o primeiro a ensinar formalmente a Matemática aos alunos e, portanto, a maneira como compreende e ensina o conteúdo matemático influencia diretamente a aprendizagem desses.

Reconhecemos a relevância da criação de espaços e tempos de discussão, entre e com os professores, para que entendimentos e ações conjuntas nas escolas favoreçam a aprendizagem dos alunos.

Diante das reflexões oriundas do grupo de discussão, sugerimos que futuras formações continuadas com professores que ensinam Matemática nos Anos Iniciais do EF destinem-se a estudos mais aprofundados sobre os conteúdos matemáticos, recursos metodológicos e currículo, especialmente com base na BNCC, a fim de proporcionar maior segurança aos professores e, assim, auxiliar no processo de aprendizagem das crianças. 


\section{Referências}

ABRAHÃO, A. M. C.; SILVA, S. A. F. DA. Pesquisas sobre a formação inicial do professor que ensina Matemática no princípio da escolarização. Zetetike, v. 25, n. 1, p. 94-116, 30 abr. 2017. Disponível em: $<$ https://www.periodicos.sbu.unicamp.br/ojs/index.php/zetetike/article/view/864774 2>. Acesso em 08 out. 2019.

AGUIAR, M. A. S. Relato da Resistência à Instituição da BNCC pelo Conselho Nacional de Educação Mediante Pedido de Vista e Declarações de Votos. In: AGUIAR, M. A. S.; DOURADO, L. F. (Org). A BNCC na contramão do PNE 20142024: avaliação e perspectivas. [Livro Eletrônico]. Recife: ANPAE, 2018.

ALARCÃO, I. Do Olhar Supervisivo ao Olhar sobre a Supervisão. In: RANGEL, M. (Org.). Supervisão Pedagógica: Princípios e Práticas. Campinas, SP: Papirus, 2001.

ALARCÃO, I. Ser Professor Reflexivo. In: ALARCÃO, I. (Org.) Formação Reflexiva de Professores: Estratégias de Supervisão. Porto: Porto Editora, 1996.

ALMEIDA, M. B.; LIMA, M. G.. Formação inicial de professores e o curso de Pedagogia: reflexões sobre a formação Matemática. Ciênc. educ. (Bauru), Bauru , v. 18, n. 2, p. 451-468, 2012. Disponível em: $<$ http://www.scielo.br/scielo.php?script=sci_arttext\&pid=S1516-

$73132012000200014 \& \operatorname{lng}=$ en\&nrm=iso >. Acesso em 21 ago. 2019.

BALL, D. L.; THAMES, M. H.; PHELPS, G. Content knowledge for teaching: what makes it special? Journal of Teacher Education, Michigan, v. 59, n. 5, p. 389-407, November/December, 2008.

BALL, D.; BASS, H. Toward a practice-based theory of mathematical knowledge for teaching. In: DAVIS, B.; SIMMT, E. (Eds.). Proceedings of the 2002 Annual Meeting of the Canadian Mathematics education Study Group. Edmonton, AB: CMESG/GCEDM, 2003.

BENTO GONÇALVES. Concurso Público - Edital de Abertura no 04/2018. 2018. Disponível em: $<$ http://www.bentogoncalves.rs.gov.br/downloads/Concurso/Concurso0042018/Concurso-04-2018-Edital.pdf>. Acesso em 07 out. 2019.

BRASIL. Ministério da Educação. Base Nacional Comum Curricular. Brasília, DF: MEC/CNE, 2017.

BRASIL. Ministério da Educação. BNCC em Planilha. Brasília, DF: MEC, [2018a]. Disponível em: < http://download.basenacionalcomum.mec.gov.br/>. Acesso em 02 ago. 2018.

BRASIL. Ministério da Educação. Secretaria de Educação Básica. Secretaria de Educação Continuada, Alfabetização, Diversidade e Inclusão. Conselho Nacional da 
Educação. Diretrizes Curriculares Nacionais Gerais da Educação Básica. Brasília, DF: MEC/SEB/DICEI, 2013.

BRASIL. Ministério da Educação. Secretaria de Educação Fundamental. Parâmetros curriculares nacionais: Matemática. Brasília, DF: MEC/SEF, 1998.

CUNHA, D. R. A Matemática na formação de professores dos anos iniciais do Ensino Fundamental: relações entre a formação inicial e a prática pedagógica. 2010. Dissertação. (Mestrado em Educação em Ciências e Matemática). Porto Alegre: PUCRS, 2010.

CURI, E. Formação de professores polivalentes: uma análise de conhecimentos para ensinar Matemática e de crenças e atitudes que interferem na constituição desses conhecimentos. Tese. (Doutorado em Educação Matemática). Pontifícia Universidade Católica de São Paulo. São Paulo: PUCSP, 2004.

FREIRE, P. Pedagogia da autonomia: saberes necessários à prática educativa. São Paulo: Paz e Terra, 1996.

GODINO, J. Categorías de Análisis de los conocimientos del Profesor de Matemáticas. Unión: revista iberoamericana de educación matemática, n. 20, p. 1331. Dez. 2009. Disponível em: https://www.researchgate.net/publication/40910173_Categorias_de_Analisis_de_los _conocimientos_del_Profesor_de_Matematicas>. Acesso em 02 out. 2019.

HILL, H. C.; ROWAN, B.; BALL, D. L. Effects of teachers' mathematics knowledge for teaching on student achievement. American Education Research Journal, Boston, v. 42, n. 2, Outubro, 2005.

IMBERNÓN, F. M. Formação docente e profissional: formar-se para a mudança e a incerteza. São Paulo: Cortez, 2010.

LOPES, A. C. Apostando na Produção Contextual no Currículo. In: AGUIAR, M. A. S.; DOURADO, L. F. (Org). A BNCC na contramão do PNE 2014-2024: avaliação e perspectivas. [Livro Eletrônico]. Recife: ANPAE, 2018.

MORAES, R.; GALIAZZI, M. C. Análise Textual Discursiva. Ijuí, RS: Unijuí, 2007.

OLIVEIRA, G. M. A Matemática na Formação Inicial de Professores dos Anos Iniciais: Uma Análise de Teses e Dissertações Defendidas entre 2005 e 2010 no Brasil. Dissertação (Mestrado). Universidade Federal do Rio de Janeiro. Rio de Janeiro: UFRJ, 2012.

OLIVEIRA, I. B. Políticas Curriculares no Contexto do Golpe de 2016: Debates Atuais, Embates e Resistências. In: AGUIAR, M. A. S.; DOURADO, L. F. (Org). A BNCC na contramão do PNE 2014-2024: avaliação e perspectivas. [Livro Eletrônico]. Recife: ANPAE, 2018.

ORNELAS, J. F.; SILVA, L. C. O Ensino Fundamental a BNCC: Proposta de um Currículo na Contramão do Conhecimento. Rev. Espaço do Currículo (online), João 
Pessoa, v.12, n.2, p. 309-325, maio/ago. 2019. Disponível em: $<$ https://periodicos.ufpb.br/ojs/index.php/rec/article/view/ufpb.19831579.2019v12n2.43516/22624>. Acesso em 01 out. 2019.

PASSOS, C. L. B.; NACARATO, A. M. Trajetória e perspectivas para o ensino de matemática nos anos iniciais. Estud. av. São Paulo, v. 32, n.94, p.119-135, dezembro de 2018. Disponível em < http://www.scielo.br/scielo.php?script=sci_arttext\&pid=S0103$40142018000300119 \& \operatorname{lng}=$ en\&nrm=iso $>$. Acesso em 23 set. 2019.

PIMENTA, S. G. O estágio na formação de professores: unidade teoria e prática? 2. ed. São Paulo: Cortez, 1995.

PIMENTA, S. G. Pesquisa-ação crítico-colaborativa: construindo seu significado a partir de experiências com a formação docente. Educação e pesquisa, São Paulo, v. 31, n. 3, p. 521-539, set./dez. 2005.

PONTE, J. P.; OLIVEIRA, H. Remar contra a maré: a construção do conhecimento e da identidade profissional na formação inicial. Revista da Educação, Lisboa, v.11, n.2, p.145-163, 2002.

ROLKOUSKI, E. Dos Direitos de Aprendizagem e do Pacto Nacional pela Alfabetização na Idade Certa à Base Nacional Comum Curricular: o caso da alfabetização matemática. Horizontes, v. 36, n. 1, p. 119-131, jan./abr. 2018. Disponível em: https://revistahorizontes.usf.edu.br/horizontes/article/viewFile/628/280>. Acesso em 01 out. 2019.

SCHÖN, D. Educando o profissional reflexivo: um novo design para o ensino e a aprendizagem. Porto Alegre: Artmed, 2007.

SERRAZINA, M. L. M. Conhecimento matemático para ensinar: papel da planificação e da reflexão na formação de professores. Revista Eletrônica de Educação. São Carlos, SP: UFSCar, v. 6, no. 1, p. 266-283, mai. 2012. Disponível em: $<$ http://www.reveduc.ufscar.br/index.php/reveduc/article/view/355/162>. Acesso em 08 out. 2019.

SHULMAN, L. Conhecimento e ensino: fundamentos para a nova reforma. Cadernos Cenpec. Nova série, [S.1.], v. 4, n. 2, dez. 2014. Disponível em: < http://cadernos.cenpec.org.br/cadernos/index.php/cadernos/article/view/293 >. Acesso em 24 jul. 2019.

TARDIF, M. Saberes docentes e formação profissional. 17. ed. Petrópolis, RJ: Editora Vozes, 2014.

VERGARA, Sylvia C. Projetos e relatórios de pesquisa em administração. 3.ed. Rio de Janeiro: Atlas, 2000.

ZEICHNER, K. Formação de professores reflexivos para a educação centrada nos alunos: possibilidades e limites. In: BARBOSA, R. L. L. (Org.). Formação de 
educadores: desafios e perspectivas. São Paulo: Unesp, 2003.

ZEICHNER, K. Novos caminhos para a prática: uma perspectiva para os anos 90. In: NÓVOA, A. (Org.). Os professores e sua formação. Lisboa: Dom Quixote, 1997.

Recebido em dezembro de 2019.

Aprovado em fevereiro de 2020. 